\title{
The Real Development of the Management Staff at Secondary School in Tri Ton District, An Giang Province
}

\author{
Thang Bach Nguyen ${ }^{1,2}$ \\ ${ }^{1}$ Faculty of Education, An Giang University, \\ ${ }^{2}$ Vietnam National University - Ho Chi Minh City, Vietnam
}

\begin{abstract}
It has been an urgent need for the Development of the management staff of Tri Ton secondary schools recently. The author has conducted a real survey of the development of the leader Group at secondary schools, thereby identifying subjective and objective causes in the development of this Group; accordingly, the author proposes in implementing the plan to develop the staff of managers at secondary schools to meet the requirements of educational innovation.
\end{abstract}

Key words: status, development, management staff, Secondary school, Tri Ton district, An Giang province.

\section{Introduction}

To develop the management staff of Secondary schools to meet the requirements of education innovation is necessary. Theadministrator is the directing implementing and examining force in educational innovation. Therefore, fostering and developing the decicion maker is an urgent and practical job contributing to the improvement and the educational quality of Tri ton District in the international integration period.

\section{Literature Review}

\subsection{Management}

According to the Vietnamese dictionary, the management is "the organizing control of operation of a unit, an agency" (Nguyen, N. Y. 1999).

The authors Harold Koontz, Cyril-Odonnel, and Heinz Weihriech (1994) claimed that management is the design and maintenance of an environment in which individuals working together in groups are able to accomplish planned tasks and objectives. The French author Henri Fayol (18411925), who laid the foundations for classical organizational reasoning, said: Management is planning, organizing, commanding, coordinating and testing. This is a generalization concept of management functions.

In consideration as an act, "management is an organized impact, which has the target of management subject to the management subject to achieve the objectives" (Bui, M. H, Vu, N. H, \& Dang, Q. B, 2006, p. 12). The author Tran, K (2004) said that: management is the directional impact, which plans the management of the subject to be managed in the organization to operate the organization, to achieve a particular purpose.

\subsection{School management}

School management is a social design which takes place in the education training process with the interactive operation of two factors teacher - student. The school is a part of the community and in the machine of the national education system; it is the base unit (Dang, Q. B, 1996, p. 3).

School management is implementing the party's educational path within its responsibilities, i.e. bringing the school to operate under the principle of education to advance to the educational goals, training objectives for the education sector, with the young generation and with each student (Pham, M. H, 1996).

\subsection{Management officers and management} staffs

\subsubsection{The administrator}

The administrator is "a person who works in an office, an organization, distinguished from a person without a ministry" (Nguyen, N. Y, 2000, p. 185).

The author Tran, K, (2004) said that Manager is the individual who performs certain management functions and tasks of an organization. The Manager is a management owner, consisting of people who take the role of motivation, order and test the management object. The Manager is the person who guides the operation of a part or the entire organization to effectively organize and achieve the purpose. The manager is both the leader and manager 
of the agency who has just been under the leadership of upper manager.

\subsubsection{The administrator Group}

According to the Vietnam Polytechnic Dictionary (2003, p. 339), "The group is a number of people who are organized and gathered together", or the team is a collection of people having the same professional functions. The concept of the team/ group is widely used in social organizations such as the intellectual team, teachers, volunteers, etc.
3. The real development of the administrator Group at Secondary School in Tri Ton District

3.1 The planning and development of management staff

The real planning and development of the administrator Group in Tri Ton district shown through table 3.1 .

Table 3.1 Results of the investigation of the planning management staff at Secondary Schools in Tri Ton District from 2015 to 2019.

\begin{tabular}{|c|c|c|c|c|c|c|c|}
\hline & \multirow[t]{2}{*}{ Contents } & \multicolumn{4}{|c|}{$\begin{array}{c}(50) \\
\text { Number of Grading People } \\
\end{array}$} & \multirow{2}{*}{$\begin{array}{l}\text { Number of } \\
\text { points }\end{array}$} & \multirow[t]{2}{*}{ Average } \\
\hline & & Excellent & Good & medium & Weak & & \\
\hline 1 & $\begin{array}{l}\text { Awareness of the importance of } \\
\text { developing HIGH school staff }\end{array}$ & 27 & 10 & 12 & 1 & 163 & 3,3 \\
\hline 2 & $\begin{array}{l}\text { Develop a plan to develop the HIGH } \\
\text { school staff }\end{array}$ & 9 & 12 & 21 & 8 & 122 & 2,4 \\
\hline 4 & $\begin{array}{l}\text { Develop specific standards for } \\
\text { selection of subjects included in the } \\
\text { planning area }\end{array}$ & 5 & 12 & 24 & 9 & 113 & 2,3 \\
\hline 5 & $\begin{array}{l}\text { Reviewing, adjusting, and } \\
\text { supplementing the planning to } \\
\text { promote staff, teachers striving to rise } \\
\text { up }\end{array}$ & 0 & 10 & 19 & 21 & 89 & 1,8 \\
\hline 6 & $\begin{array}{l}\text { The discovery and introduction of } \\
\text { sources for the development of staff }\end{array}$ & 5 & 26 & 12 & 7 & 129 & 2,6 \\
\hline & An arithmetical mean & & & & & & 2,5 \\
\hline
\end{tabular}

The figures found in the table 3.1, indicating the actual planning work on the development of management staffs at Secondary school in Tri Ton, An Giang Province with anarithmetical mean of 2.5. The best activity is "awareness of the importance of developing the high school staff"; The weakest is "reviewing, adjusting, and supplementing the planning to promote staff, teachers striving to rise up" only an average score of 1.8.

To implement the planning of the management staff in Tri Ton's Secondary Schools, The Tri Ton District Education and Training Departmenthas been based on the provisions of the Organizing committee of the District, the interior and the guidelines of The Department of Education and Traning of An Giang province on planning and enacting the propose for development of the school staff in the period 2015-2020 for the whole district. On the forecasting for the development of number of school; Secondary School manager standards requirement for managers; analysis drawbacks and advantages; Requirement about quantity, structure, quality of director team. Base on these factors, The Secondary schools make a plan send it to the authority to approve as a base for fostering and using. Every year, the Secondary schools are required to report the reviewing and listing to The District Education and Training Department who then report to People's Committee and Department of Education and Training of An Giang Province.

3.2 Recruitment and use of the administrator group

As the figures found in the table 3.2: The actual status of the selection, using the school staff in Tri Ton District, An Giang Province is at the average rate (the average score the surveyed activities are 2.04). The weakest activity is "appointment and reappointment of manager to ensure the the specified time and proper process", only achieving an average score of 1.72; The remaining four operations were also at moderate rate, with an average score of between 2.0 and 2.2. It is noteworthy that no activity reaches above good level.

Through an interview with the manager at secondary School and Professional staff at District Education and Training Department, there are several following limitations: 
Table 3.2 Results of the investigation of the the selection management staff at Secondary Schools in Tri Ton District from 2015 to 2019.

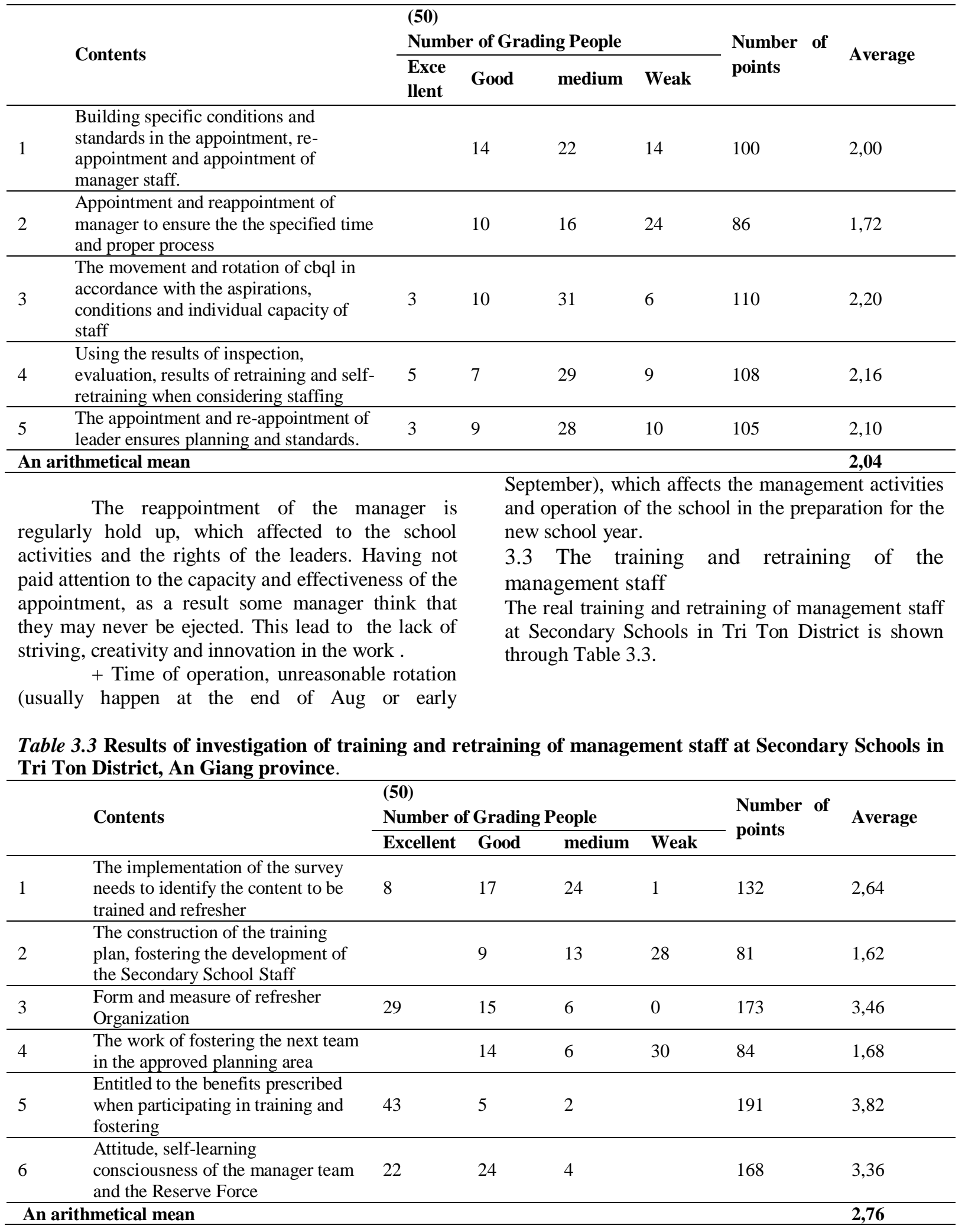

The figures found in table 3.4 , indicating the real problem of training, fostering the manager staff at secondary school in Tri Ton District, An Giang Province. Generally, the average score is quite Good
(2.76). Among them, the best actitity is "entitled to the benefits prescribed when participating in training and fostering" (3.82); Second, "attitude, self-learning consciousness of the manager team and the Reserve 
Force" (3.36) and the "form and measure of refresher Organization" (3.46). "The implementation of the survey needs to identify the content to be trained and refresher" is at Good level (2.64). However, there are two activities that are below average rate are "the construction of the training plan, fostering the development of the SECONDARY School Staff" (1.62) and "The work of fostering the next team in the approved planning area" (1.68).

Thereby, in term of training content, fostering the school leader of the district has been done quite

well, up to $4 / 6$ activities are surveyed at moderate and good level, 2/6 activities are still poor. By interviewing, there are still some limits, as follows:

+ In terms of training content survey, despite being at moderate rate but in fact these content is mainly used by the Province Department of \& Education and Traning, applied collectively to the province during the annual summer refresher, the representative of each district participated in the training then reported for the entire district. In the reality, the district has not actively surveyed the requiremnen to determine the content of train, fostering for individual districts on the basis of assessment according to management activities in the District.

+ The District Department of \& Education and Traning and Secondary schools have not built a plan for training and fostering managers at their school, which leads to the lack of organizing classes base on real demand and especially content related to the management of the school is still weak.

3.4 The inspection and evaluation of the management group

The data in Table 3.4 showed that the actual inspection and evaluation of the management Group at Secondary school in Tri Ton, An Giang province was generally evaluated at an arithmetical mean of 2.56. The best-rated activities are "Inspection of school management activities of superiors for staff" (3.48) and "The granting of management documents for adjustment after each inspection and evaluation" (3.44).

"Coordination with local authorities in assessing staffing according to the Standard' was also assessed at Good rate (2.98). The two activities assessed at medium level are "Assessment of Principal Standards of The Department of Education and Training for Secondary School Staff' (1.98) and "The use of assessment results to consider promotion, appointment, re-appointment, rotation, movement" (1.94). It is noteworthy that the "Inspection of the implementation of the manager team development plan" was assessed at a weak level, achieving an average score of only 1.42 .

Table 3.4 Results of the survey of the inspection and evaluation of the management Group at Secondary school in Tri Ton, An Giang province.

\begin{tabular}{|c|c|c|c|c|c|c|c|}
\hline & \multirow[t]{2}{*}{ Contents } & \multicolumn{4}{|c|}{$\begin{array}{l}\text { (50) } \\
\text { Number of Grading People }\end{array}$} & \multirow{2}{*}{$\begin{array}{l}\text { Number of } \\
\text { points }\end{array}$} & \multirow[t]{2}{*}{ Average } \\
\hline & & Excellent & Good & medium & Weak & & \\
\hline 1 & $\begin{array}{l}\text { Inspection of school management } \\
\text { activities of superiors for staff }\end{array}$ & 29 & 16 & 5 & & 174 & 3,48 \\
\hline 2 & $\begin{array}{l}\text { The inspection of the implementation } \\
\text { of the staff development plan }\end{array}$ & & 3 & 15 & 32 & 71 & 1,42 \\
\hline 3 & $\begin{array}{l}\text { Evaluation of Principal Standards of } \\
\text { The Department of Education and } \\
\text { Training for Secondary School Staff }\end{array}$ & 5 & 9 & 16 & 20 & 99 & 1,98 \\
\hline 4 & $\begin{array}{l}\text { Coordinating with local authorities in } \\
\text { assessing staff in accordance with }\end{array}$ & 16 & 17 & 17 & & 149 & 2,98 \\
\hline 5 & $\begin{array}{l}\text { The promulgation of management } \\
\text { documents for adjustment after each } \\
\text { inspection and evaluation }\end{array}$ & 29 & 14 & 7 & 0 & 172 & 3,44 \\
\hline 6 & $\begin{array}{l}\text { The use of assessment results to } \\
\text { consider promotion, appointment, re- } \\
\text { appointment, rotation, }\end{array}$ & & 7 & 33 & 10 & 97 & 1,94 \\
\hline \multicolumn{7}{|c|}{ An arithmetical mean } & 2,56 \\
\hline
\end{tabular}

Through interviews with secondary school staff and experts of the District Education and Training Department, it is known that the Department of Education and Training is very interested in the inspection of school management activities for leader's staff, every year there are plans for periodically checked, unscheduled inspections and thematic examination of the implementation of the guiding contents, especially new content, important content. At the end of each inspection, there is a notice of inspection results and a specific written direction to all schools to be agreed on the issue that has been examined. However, the inspection and evaluation of this group still has some limitations as follows:

+ The District Education and Training Department has not annually checked the implementation development plan. 
+ Not yet attaching the results of examination and evaluation with the classification of managers to make training and retraining plans; layout and arrangement, team screening.
3.5 Implementation of policies for the management staff

Table 3.5 Results of investigation of the implementation of policies for staff at Tri Ton's secondary school, An Giang province.

\begin{tabular}{|c|c|c|c|c|c|c|c|}
\hline & \multirow[t]{2}{*}{ Contents } & \multicolumn{4}{|c|}{$\begin{array}{l}\text { (50) } \\
\text { Number of Grading People }\end{array}$} & \multirow{2}{*}{$\begin{array}{l}\text { Number } \\
\text { of points }\end{array}$} & \multirow[t]{2}{*}{ Average } \\
\hline & & Excellent & Good & medium & Weak & & \\
\hline 1 & $\begin{array}{l}\text { The implementation of policies in accordance } \\
\text { with general regulations for staff }\end{array}$ & 45 & 5 & & & 195 & 3,9 \\
\hline 2 & $\begin{array}{l}\text { Building policies regime to attract good staff } \\
\text { in accordance with local characteristics }\end{array}$ & & 8 & 10 & 32 & 76 & 1,52 \\
\hline 3 & $\begin{array}{l}\text { The detection of violation handling of } \\
\text { managers promptly, strictly }\end{array}$ & & 9 & 21 & 20 & 89 & 1,78 \\
\hline 4 & $\begin{array}{l}\text { Having policies to encourage high-quality } \\
\text { human resources }\end{array}$ & 19 & 25 & 5 & 1 & 162 & 3,24 \\
\hline \multicolumn{7}{|c|}{ An arithmetical mean } & 2,61 \\
\hline
\end{tabular}

The data in Table 3.5, showing the status of the implementation of the regime and policies for the management staffs of Tri Ton Secondary School, An Giang province is generally evaluated with an arithmetical mean of 2.61. The best-rated activities are "The implementation of policies in accordance with general regulations for staff" (3.9) and "Having policies to encourage high-quality human resources" $(3,2)$. The medium rating is "The detection of violation handling of managers promptly, strictly" (1.8) and the lowest is "Building policies to attract good staff in accordance with local characteristics" only achieved an average score of 1.8 .

Through interviews with secondary school's managers and experts of Tri Ton District Education and Training Department: The policies prescribed for the administratorsare interested by the District Education and Training Department, fully and promptly solved in accordance with regulations, helping the team to be assured of working. However, this work has some limitations as follows:

+ The District has not yet developed its own particular policy in accordance with the characteristics of a mountainous district; ethnic minority areas still have many difficulties to attract high-quality human resources. Especially, the attractive policy for the management staff of the schools. In order to achieve good qualification, this leader force must be trained, fostered and accumulated practical experience in the long run. If there is no long-term retention policy, it is easy to lead to shortage of staff resources for the district in the long run.

\section{Assessing the real situation of development of secondary school administrators in Tri Ton district, An Giang province.}

Through the results of the real survey on the the development administrators at Secondary School in
TriTon, there are some basic strengths and limitations as follows:

\subsection{The Advantages}

The development of the administrators staffs has been interested in, directed at quite a full range of contents such as: planning; selection and use; training and retraining; inspection and evaluation; implementing the policies, contributing to improving the quality of secondary school staff in the area.

The planning for the development of secondary administrators received the attention of the commissioner and local authorities. The district has developed a team planning plan and deployed to all district educational institutions for implementation. The schools have implemented and carried out the plan and reviewed annually as prescribed. In the planning, it should be paid more attention to female and ethnic minority cadres. The list of plannings is synthesized by the Department of Education and Training of district and approved by the competent authorities as a basis for training, retraining and considering the layout of use.

The appointment and re-appointment of administrator is carried out in accordance with regulations, there is coordination between the Department of Education and Training and the Interior Department of district in the process of presenting the district People's Committee for approval of the Decisions. Every year, the district has rotated and transferred leaders to harmonize the quality and create conditions for them to foster and train in the management of the school.

The inspection and evaluation of the administrator group performed quite well, the management activities of the staff were checked periodically, unexpectedly and concluded in writing by the management agency. The standard assessment for school's leaders is carried out in the spirit of Circular 14/2018/TT-BDDT of the Ministry of Education and Training. 
The policies for teachers in general and managers in particular are fully implemented, timely to help the team peace of mind.

\subsection{Disadvantages}

The planning of secondary school manager's group: The standards of the staff included in the planning have not been specified, so they are still passive and confused when implementing; lack of quantity; have not boldly rejuvenated the team; the most structurally unstructioned is that the cadres are ethnic minorities. This is something that needs to be taken care of in the upcoming time because of the particular's characteristics of the district: having 7 communes and towns with large ethnic minority, the planning of ethnic minority staff to create a source of staff later arranged work in these regional schools is very necessary.

The appointment and re-appointment of administrator does not have a specific process and taking time. Re-appointment of administrator is sometimes slow, at the end of the term but has not yet implemented the re-appointment process. The appointment and re-appointment is still lack of standards (politics), not associated with the results of assessment examinations and performance should affect the quality of administrator, not screened the team.

The contents of training and retraining for administrator also depend on the Department of Education and Training of province, not yet build their own contents based on the results of inspection, evaluation and the limitations and practical weaknesses of the team in the process of school management. The training and retraining for the team in the planning area has not been properly concerned yet.

The inspection and evaluation have not been interested in checking the implementation of the development plan of the management staff of the schools, not attaching the results of inspection and evaluation with the planning, training and layout of use.

There is no particular policy to attract highquality human resources to long-term work.

\subsection{Causes}

\subsubsection{Causes of success}

The District has fully implemented the steering documents on the development of education and training, including the development of teachers and educational administrator's staff of the Party and the State issued as: Directive 40/2004/CT-TW on $15 / 6 / 2004$ of the Secretariat, on the construction and quality of teachers and staff Resolution No. 29NQ/TW on 04/11/2013 of the Central Committee, on fundamental and comprehensive innovation of education and training, meeting the requirements of industrialization and modernization in the conditions of socialist-oriented market economy and
ISSN 2455-6378

international integration; Decision No. 732/QD-TTg on April 29, 2016 of the Prime Minister on approving the project "Training and retraining teachers and managers of educational institutions to meet the requirements of fundamental and comprehensive renovation of general education in the period of 2016-2020, oriented to 2025".

Most of the managers at all levels of education, Secondary schools and teachers have the right perception of the role, the importance of the development of the high school manager's group has the spirit of responsibility, love their own profession to raise the spirit of self-study, forging selfimprovement to meet the requirements of education and tranning development.

\subsubsection{Causes of drawbacks}

Although the development of the secondary school's manager is concerned with the local committee and government, It is still not well developed. Insufficient inspection of the implementation the contents of the development of this Group.

Has not yet built the specific rules of appointment, reappointment of the educational leaders; Sometimes sensibility, having regard and localization in the planning, selection and use of officers.

The Policies for educators, managers is changed slowly, and has not caught up with socioeconomic development. Districts in the mountains and ethnic regions are having a lot of difficulties. In addition, there is no specific policy in accordance with the particular district, so it is hard for attracting hight-quality human resources.

The District Education and Training Department has not completely done its role and function in the development of decision makers at secondary school. Some managers lack sense of responsibility and self-study spirit.

\section{Conclusion and Suggestion}

\subsection{Conclusion}

From the results above, the study may draw to the following conclusions:

The administrator at Secondary school is an important force, play an important role in leadership and management in the Secondary schools. They are tasked directly who are directing and operating the entire Secondary school education, so the quality of the team should be concerned to ensure that the school performs the objectives and duties of the prescribed level. Therefore, developing this force is a very necessary work to improve the quality and efficiency. The essence of developing this Team is to help them become enough in terms of quantity, synchronization of structure, ensure the quality, afford to take on the assigned tasks.

On the basis of the theoretical content of science management and education management, it 
is possible to determine the content of development in the context of educational innovation as follows: Based on the requirements for innovation and education development of the each level, based on the standar criterion for Principal, the selection, arrangement and using the managers in a reasonable way, training as well as fostering this Group so that they can meet the educational innovation requirement; Testing and evaluation so that the team always responds to the request for assigned tasks; There is a reasonable incentive policy, which gives motivation to actively work.

The results of the survey about the school's leader in Tri Ton showed that: the manager's team here is basically enough in quantity, has a reasonable structure in terms of age and seniority. This Group has a moral political qualities, good lifestyle and standard level of training; has full capacity to complete the prescribed school management tasks. However, They still have certain limitations: insufficient in quantity; Interm of the structure: there is lack of young leader, female officials, minority officials, limited in terms of operating capacity in some areas of management, below the basic standar level of training (in politics and education, foreign languages).

\subsection{Suggestion}

5.2.1. For Department of Education and Training of An Giang Province

When developing annual refresher plans, manager's team from districts need to be surveyed to properly identify the content that the institution is in need of, lack of information or restriction in the process of implementation. Help leaders at the educational institutions improve knowledge and experience in performing the task.

Annually, review, re-evaluate the policy regime relating to educators and school's managers which considers as a basis for proposing the Province People Committee, Governmnet to adjust and add of new policies on training and fostering, etc. suitable to the actual situation, creating more motivation to boost the team's development to meet educational innovation requirements.

Frequently contact with reputable, experienced training facilities to open the professional refresher courses for the managers. Pay attention to the choice, order more specialized refresher topics in accordance with local particularity and the status of the leader group.

\subsubsection{For Tri Ton District People's Committee}

To strengthen direction and examine the planning and development of the school's managers in the communes and towns.

Clearly assign functions, duties, powers and responsibilities of the District Education and Training Department and the Interior Department in the selection for leader position actively, well

\section{ISSN 2455-6378}

coordinate between the two agencies in the counsel to the People's Committee on the state Management of Education \& Traning.

Assigning the District Education and Training Department and Interior Departments in the specialization of personnel procedures, specific standards in accordance with the rules of the profession, local area which is easy for implementation and assurance on the order, procedure, time prescribed.

Reviewing the proposals and recommendations of the education industry in building the policy mode of attraction, encouraging advanced level... for educators and school's leaders.

\subsubsection{For Tri Ton District Education and Training Department}

Enhancing the implementation of the team development plan, planning and evaluation base on the standards criteria of the school, timely support the school to solve difficulties and obstacles.

Actively coordinate with Personel Department to construct the processes of personnel work of education staff, giving advises for the People's Committee of the District approves and issues unified implementation.

The organization identifies and builds the specific system of evidence for each criterion for the principal, teachers the standard, to ensure the general regulations of the profession and the real of the district, to help the assessment is more accurate, reflects the true capacity of school's leader, teachers, build up training plan, nurture, organize, sift and execute the main regime for the current and the potential people.

More interested in traning the potential manager forces in the district, ensuring that this force is fully fostering the standards of the planning title, proceeding to the non-appointment, re-appointment of unqualified school manager.

\subsubsection{For secondary schools and school administrators of Tri Ton district}

The managers, teachers are arranged and facilittated to be participated in learning advanced educational management level; professional qualifications; Equipped with facilities and favorable working conditions for the school to fully complete all tasks and meet the requirements of education innovation.

When building the regulation of internal spending of the unit, people should specify the mode of supporting fund for manager, teachers who are self-study to encourage them to raise their qualification (masters).

Each of the managers should clearly define their role, responsibilities at their schools, in their local in the current education innovation. Since then, each leader officers needs to change the perception about their role, their responsibility, to be able to show the active role, exemplary, determination, 
positive in the innovation. In order to do this well, each teacher himself, each manager must constantly improve their own capacity to meet the requirements of professional standards, actively study to improve quarlification, skills in professional service, management skills; To appreciate self-study, self research, etc.

\section{Reference}

[1] Dang, Q. B (1998). The Overview of Organization and Management, Publishing House, Ha Noi, Vietnam.

[2] Dang, Q. B (1996). With regard to school category and school developing task in the present context. The Education Publishing House, Ha Noi, Vietnam.
[3] Pham, M. H (1996). Ten years for renovating Education and training. The Education Publishing House, Ha Noi, Vietnam.

[4] Ha, T. N. (2001). Pedagogy, some problems of reasoning and reality. Ha Noi National University Publishing House, Hanoi, Vietnam.

[5] Harold Koontz, Cyril-Odonnel, Heinz Weihriech.(1994), The essential problems of management. Ha Noi technology Science Publishing House, Hanoi, Vietnam.

[6] Tran, K. (2004). The science of education management, some problems of reasoning and reality. The Education Publishing House, Hanoi, Vietnam.

[7] Nguyen, N. Y. (2000). The great Vietnamese dictionary. The Information - Culture Publishing House, Hanoi, Vietnam. 